\title{
Cultural diversity drives innovation: empowering teams for success
}

\author{
Graham Jones
}

TRD Innovation, Novartis Pharmaceuticals Corp, East Hanover, New Jersey, USA

Bernardita Chirino Chace

TRD Innovation, Novartis AG, Basel, Switzerland, and

Justin Wright

TRD Innovation, Novartis Pharmaceuticals Corp, East Hanover, New Jersey, USA

\section{Cultural diversity drives innovation}

Received 12 April 2020 Revised 30 June 2020 6 August 2020 Accepted 10 August 2020

\begin{abstract}
Purpose - Though there is broad agreement on the beneficial impact of diversity in management and leadership roles, much of the innovative capacity of an organization is realized at the unit level in working teams. Recent research points to cultural diversity having an especially significant impact on innovation team performance. The reports also highlight the need for the optimal team operating principles to derive maximum benefit. To prepare such innovation teams for success, it is valuable to understand the dynamics of team diversity at the project level and the underlying barriers and opportunities presented.

Design/methodology/approach - This paper reviews the literature and case studies on cultural inputs to ideation and innovation, assessing team diversity through readily available instruments and the deployment of the science of team science (SciTS) principles in innovation teams.

Findings - The key learnings include the importance of establishing communication standards, SciTS principles, team assessment of thinking styles and the utility of cultural awareness instruments.

Practical implications - Diversity provides a creative advantage for innovation teams. However, team dynamics play an important role in maximizing these advantages, and cross-cultural competence of team members is required. Deployment of appropriate assessment tools and team methodologies enhances the likelihood of successful outcomes including in remote team settings.

Originality/value - Literature from diverse functional areas is summarized including the science of team science, organizational management, diversity and inclusion methodologies and ethnocultural dynamics. It provides pointers for the optimal formation and operating principles with highly culturally diverse teams.
\end{abstract}

Keywords Implementation, Assessment, Innovation, Culture, Diversity, Inclusion, Ideation, Team science

Paper type General review

\section{Impact of diversity on innovation}

Numerous studies confirm the positive impact of diversity at board level, executive leadership and managerial roles in organizations. In the case of innovation, in addition to

(C) Graham Jones, Bernardita Chirino Chace and Justin Wright. Published by Emerald Publishing Limited. This article is published under the Creative Commons Attribution (CC BY 4.0) license. Anyone may reproduce, distribute, translate and create derivative works of this article (for both commercial and non-commercial purposes), subject to full attribution to the original publication and authors. The full terms of this license may be seen at http://creativecommons.org/licences/by/4.0/legalcode

The authors wish to thank Elena Rodriguez, Anastacia Awad, Ivonna Demme, Nancy Long, Christian Pihlgren, Unmesh Deodhar, Rahul Sharma and Clara Fernandez de Castro for inputs on the manuscript.

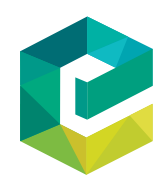

International Journal of Innovation 
IJIS

12,3

324

strategic leadership, one must of course consider the innovation process itself, which typically involves ideators and entrepreneurs from varied backgrounds who work in smaller teams driven by strategic goals (Nelson, 1991). Diversity of thought and approach are naturally assumed to be beneficial to the innovation process, which by its very nature thrives on creative tension and alternating viewpoints. Despite the potential to have a major influence on productivity and impact, relatively few dedicated studies have been reported on the links between diversity and innovation (Joecks et al., 2013). Factors to consider include, gender, cultural, ethnic, country of origin, geographic location and disciplinary diversity. Studies on gender diversity have modeled the performance impact of uniform, skewed, tilted and balanced groups, often assessed using the Blau index (Blau, 1977). Although not specifically addressing innovative potential, there is overwhelming evidence that gender heterogeneous teams produce higher quality technical and scientific outputs (Campbell et al., 2013) but concerted engagement is also needed to realize these benefits fully within organizations (Zheng, 2013). One study by the Boston Consulting Group modeled the impact of six components of diversity on innovation team performance (BCG, 2018). Conducted through a survey of $>1,700$ employees in 8 countries (Austria, Brazil, China, France, Germany, India, Switzerland and the USA) the study examined perceptions of diversity components at management level (gender, age, the nation of origin, career path, industry background and education). Two features are noteworthy. First, a statistically significant correlation was observed between innovation performance and the diversity of management teams across all six diversity indicators (approximately 20\% improvement in innovation revenues). Second, the most pronounced impact driver was the nation of origin of team members (Table 1 ).

If substantiated, this has potentially far-reaching consequences in the pharmaceutical industry where numerous multinational corporations are headquartered around the globe, and routinely assemble and engage teams (both physically and remotely) from vast and highly diverse populations. The revelation even prompted the quote "for management teams there are few slam dunks in the business world - this is one of them" (BCG, 2018). The cultural dimensions uncovered in this survey have been the subject of other research. In an unrelated study, conducted through a survey of 500 corporate executives one in two respondents believed there exists a positive correlation between cultural diversity and innovation drivers (Bertelsmann, 2018). Despite this admission, some $42 \%$ of respondents indicated that their organizations did not focus on hiring diverse workforces. The study goes on to conclude that the more varied an innovation team is in terms of country of origin the greater the impact. The authors ascribe this to employees with diverse backgrounds having specific cultural knowledge, which can be deployed to assess and solve problems in different ways, and they may also have a higher tolerance for taking risks. Caution is also signaled in that different cultural methods of interpretation and values can present challenges in team settings, as there exists the potential for misunderstanding among members. This underscores the importance of studying team dynamics to maximize potential and fully exploit the value of team diversity (vide infra). Accordingly, the impetus

Table 1.

$\%$ Leadership team appointments needed to effect a $1 \%$ increase in innovation revenue
Leaders with diverse educational backgrounds

Diversity based on age

Externally hired managers from different career paths

Appointment of female managers

Appointing managers with experience from different industries

Appointing managers from diverse nations of origin 
for assembling this review was to highlight studies, which assess the origins and impact of cultural diversity on innovation team performance, readily available instruments, which assess cultural contributions and tools which can be deployed to optimize team dynamics. Our focus area is on innovation teams and it is of course recognized that corporate innovation is guided by business drivers which may determine the composition, scope and success factors of any given team (Nelson, 1991). Nonetheless, given the significance and implications of the subject matter across various industries (BCG, 2018) it is instructive to examine even in the most general sense.

One of the most provocative and far-reaching investigations on the impact of national origins on culture, values and behavior was reported by Geert Hofstede. Hofstede's primary data was derived from 117,000 surveys conducted between 1967 and 1973 within the IBM Corporation and its subsidiaries which span a total of 66 countries. The surveys recorded employee attitudes to a variety of challenge questions and resulted in the assembly of a series of cultural maps using factor analysis, which scales propensities and preferences as a function of national origin (Hofstede, 2010). Subsequent research and validation studies in nearly 1,000 corporate populations around the globe during the period 1994-2004 (the GLOBE study) introduced additional dimensions (Hofstede, 2010), the base set of which are represented in descriptors of the six cultural dimensions proposed by Hofstede (2010):

(1) Power distance index (PDI):

- "The extent to which people expect and agree that power should be shared unequally."

- A higher degree signifies hierarchy is clearly established, a lower degree that people question authority.

(2) Individualism vs collectivism (IDV):

- "Degree to which society rewards individual versus collective action."

- Higher degrees, individualistic societies, emphasize the "I" versus the "we."

(3) Uncertainty avoidance (UAI):

- "A society's tolerance for ambiguity."

- A higher degree suggests societies, which opt for stiff codes of behavior, guidelines and laws.

(4) Masculinity vs femininity (MAS):

- "Societal preference for achievement, heroism, assertiveness and material rewards for success."

- Its counterpart values cooperation, modesty, caring for the weak and quality of life.

(5) Long-term orientation vs short-term orientation (LTO-STO):

- "A societies' connection of the past with the current and future actions/ challenges."

- In high preference, LTO traditions are honored, whereas in STO adaptation is viewed as a necessity.

(6) Indulgence vs restraint (IND):

- "Degree of freedom societal norms afford to citizens in fulfilling their human desires."

- In its counterpart, society controls gratification and regulates by means of strict social nor. 
IJIS

12,3

\section{6}

Figure 1.

Cultural Dimension maps for the six most populous nations plus Switzerland
Specimen dimensions data are presented for the six most populous nations in the world, plus Switzerland, highlighting the wide scoring ranges typically observed (Figure 1). Implicit within the data are myriad dynamic factors including religious preferences, governmental structures, historical backgrounds, philosophical beliefs, coupled with socio-economic drivers e.g. education, health, poverty, incarceration rates, etc. Obviously, due caution and judgment need to be exercised when viewing such data, as individual choices, behaviors and attitudes that are contrary to those implied by the indices will be expected and stereotypes should be avoided. Additionally, great regional differences can exist within individual countries (e.g. the USA and Switzerland) and even cities (urban v suburban). It is also recognized that nations continually evolve - the disintegration of the former Yugoslavia into culturally distinct countries being a case in point. Moreover, individuals who live in different countries during their formative years would be expected to be influenced by the multiple environments and a single point of reference could be entirely misleading.

Despite these limitations, the dimensions have received considerable attention in the business world and have resulted in a spirited debate among social science researchers (Hampden-Turner and Trompenaars, 2006; McSweeney, 2002). The impact of such cultural dimensions on innovation potential has been studied by several investigators. In one study the impact of the Hofstede dimensions on patenting activity was examined, as a surrogate for innovation activity (Kaasa and Vadi, 2010). A total of four hypotheses were challenged relative to innovation initiation and examined against primary data:

H1. There is a negative relationship between power distance and innovation.

H2. There is a negative relationship between uncertainty avoidance and innovation.

H3. There is a positive relationship between individualism and innovation.

H4. There is a negative relationship between masculinity and innovation.

\begin{tabular}{|c|c|c|}
\hline Power Distance Index & Individualism v Collectivism & Masculinity v Femininity \\
\hline CHINA & CHINA & CHINA \\
\hline 80 & 20 & $x^{2}$ \\
\hline INDIA & INDIA & INDIA \\
\hline 77 & 48 & (n) \\
\hline USA & USA & USA \\
\hline 40 & 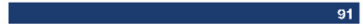 & 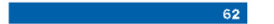 \\
\hline INDONESIA & INDONESIA & INDONESIA \\
\hline 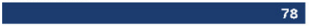 & 14 & 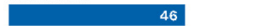 \\
\hline PAKISTAN & PAKISTAN & PAKISTAN \\
\hline 55 & 14 & 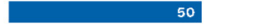 \\
\hline BRAZIL & BRAZIL & BRAZIL \\
\hline 69 & 38 & $x_{2}$ \\
\hline SWITZERLAND & SWITZERLAND & SWITZERLAND \\
\hline 34 & 68 & 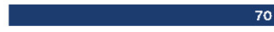 \\
\hline Uncertainty Avoidance & Long Term v Short Term Orientation & Indulgence $v$ Restraint \\
\hline CHINA & CHINA & CHINA \\
\hline 30 & 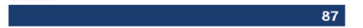 & 24 \\
\hline INDIA & INDIA & INDIA \\
\hline 40 & 51 & 26 \\
\hline USA & USA & USA \\
\hline 46 & 26 & 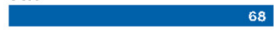 \\
\hline INDONESIA & INDONESIA & INDONESIA \\
\hline 48 & 62 & 38 \\
\hline PAKISTAN & PAKISTAN & $\begin{array}{l}\text { PAKISTAN } \\
1\end{array}$ \\
\hline BRAZIL & BRAZIL & BRAZIL \\
\hline 76 & 44 & 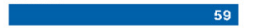 \\
\hline SWITZERLAND & SWITZERLAND & SWITZERLAND \\
\hline 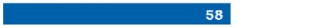 & $L_{1}$ & 66 \\
\hline
\end{tabular}


Significantly, $H 1, H 2$ and $H 4$ were supported by data regarding patenting intensity. In the case of $H 3$, though partially supported by data the authors concluded that the impact of family collectivism versus corporate collectivism complicated data sets, precluding a definitive outcome (Kaasa and Vadi, 2010). The authors advance that a reliable link between cultural dimensions and patenting intensity does exist. Obviously, caution needs to be exercised using patents as a surrogate for innovation activity as decisions to pursue are complex undertakings, requiring significant capital investment, often describing inventions a long way prior to market introduction and which in some cases are used defensively (Martínez-Piva, 2009). Nonetheless, they are generally accepted as one of several measures of performance at the so-called "fuzzy front end" of innovation or FFEI (Gassmann and Schweitzer, 2014). Additional studies have examined the impact of culture on innovation (Herbig and Dunphy, 1998), including national (Shane, 1993) and multi-nation studies (Dakhli and de Clercq, 2004), downward trends in cultural differences in Europe (Gooderham and Nordhaug, 2002) and the impact of national networks (Ahuja, 2000). Related work has mapped national culture correlations to two individual components of innovation, namely, the initiation and implementation phases (Nakata and Sivakumar, 1996). For example, the contribution of individualism (ranked high in the USA) to the first, initiation stage of innovation can be understood (ideation and concept testing), as equally can be the value of collectivism (ranked high in Japan) to the second, implementation phase of innovation (product development and launch) which requires concerted, group effort. These studies are insightful, and, coupled with comparative re-assessments between Eastern and Western cultures (Wu, 2006), have allowed researchers to correlate observed contributions to innovation with national propensities (Smale, 2016).

Though understanding the drivers and proclivities of individual contributors is instructive, an obvious challenge lies in managing the dynamics of innovation teams to establish the most creative and productive environment. Studies suggest that published outputs from diverse teams are cited more frequently than from those with less heterogeneity, and the notion that ethnic diversity reflects idea diversity has been advanced (Freeman and Huang, 2014). It has also been suggested that the management of teams with high cultural diversity may warrant special considerations within organizations (Mannix and Neale, 2005). Accordingly, when capitalizing on opportunities imbued by cultural diversity in innovation teams, attention to cultural competence of assembled teams (cultural intelligence (CQ)) should also be studied, alongside traditional evaluative (EQ and IQ) measures.

\section{Cross-cultural competence in innovation teams}

Assembling teams who hail from a multitude of diverse cultural backgrounds is a routine occurrence in modern multinational corporations, and especially prevalent in the global pharmaceutical sector. Accordingly, a degree of cross-cultural awareness and competence could be considered a natural advantage to a team member. In addition to working within the team, cross-cultural competence could also be valuable for interactions external to the organization e.g. customers, suppliers, regulators and patients in the myriad markets the team is engaged in (Ramalu et al., 2010). For these reasons, it is logical that an assembled team considers the cultural awareness and competence (CQ) of its members (Ang and van Dyne, 2008). Such insights could be reasoned to help the team establish itself and function more effectively, and would have added value within innovation teams. Creative tensions are expected and encouraged in such environments, and CQ competence could reduce the likelihood of any ad hominem behaviors by reducing potential misunderstandings and miscommunications which have cultural origins. These cultural touchpoints can range from 
IJIS

12,3

328

Figure 2.

Cultural

Relationships to

Communication

Preferences proposed by Hall (1977) subtle, interpersonal nuances through to organizational edicts and operating models and team members with experience would be able to mentor and socialize new colleagues. For example, when communicating decisions stemming from teams and units, in certain countries (e.g. India and Japan) they are sometimes pre-socialized in smaller groups to secure buy-in prior to formal announcements, whereas in others (e.g. the USA) external advisors are often engaged to make recommendations which are subsequently announced (Gibson and Gibbs, 2006). Navigating these norms requires due diligence and skill, best gained from exposure to the cultural elements in person or through structured training. Even at the most basic level, conversational styles need to be mindful of cultural norms (Ang and Van Dyne, 2008). For example, in some countries pauses in conversations are deliberate, injected to allow the parties to reflect upon and honor what was just said. Conversely, some cultures seem to promote the rapid exchange of conversational points as a sign of productivity and alignment (the USA is a good example). Accordingly, one needs to be mindful not to unintentionally show disrespect to a person based on the cadence of a conversation (Fussell and Setlock, 2012). As diligent employees will no doubt be mindful of these issues in a global corporation, they can become of special significance for the effective functioning of culturally diverse teams. Another example can be observed in the way different cultures use facial expressions to communicate (Barrett et al., 2019). While in certain western countries an exaggerated smile may be offered to an individual to express welcoming and project a degree of confidence, in other countries it can be deemed inappropriate (Coles et al., 2019). Japanese business culture values humility and suppression of emotions to convey trust, and fewer emotions are communicated using the mouth (Stanford, 2016). Smiling at a stranger in other countries can be interpreted as a sign of stupidity, insanity, insincerity or even dishonesty (Krys et al., 2016). Likewise, the application of direct eye contact can be interpreted as a sign of confidence and respect in some countries whereas in others it can signal disrespect and insubordination, requiring cultural context and awareness (Uono and Hietanen, 2015). In-depth studies have been conducted on the perceptions of facial expressions, including the so-called "Duchenne" smile and apparent disconnects between people's self-reported degree of happiness and smile tendency (Gunnery and Hall, 2014). It has also been determined that of a possible total of 16,384 possible facial configurations, only 35 are used to transmit emotive information across cultures and within these 8 are dominant in most cultures (Srinivasan and Martínez, 2018). Correlations with the Hofstede cultural dimensions have also been explored. In countries with low scores on the uncertainty avoidance dimension (UAI) non smiling individuals were deemed as more intelligent (Hareli and Hess, 2010), and second, in countries with high corruption indicators, smiling correlated with reduced levels of trust (Ozono, 2010). Another crucial factor for team members relates to communication style (Figure 2). Under the principles outlined by Hall (Hall, 1977), individuals can be categorized as either direct or indirect communicators and there are cultural underpinnings for each (Gudykunst and Ting-Toomey, 1988). Under this framework, direct communicators are seen to operate with a low situational context, with a

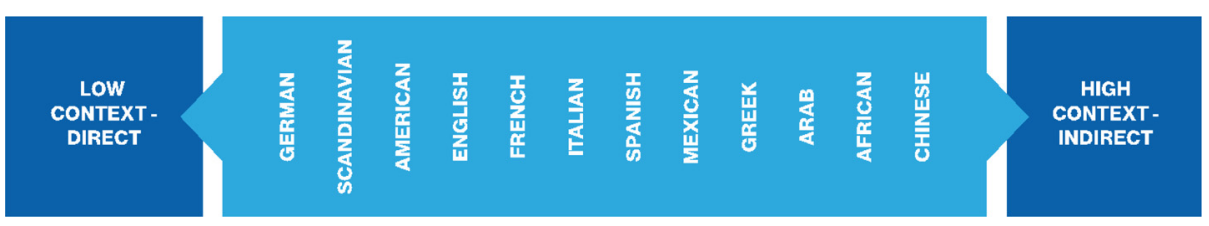


high emphasis on actual words being spoken irrespective of any possible nuances (Hall, 1977).

Conversely, an indirect communicator will place a high degree of context to the conditions under which words are spoken including tone, body language and what is not said in addition to spoken word (Clyne et al., 2009). Though most people function as a blend of the two, extreme differences between the two approaches can naturally lead to conflict or misunderstanding in team settings, e.g. where an email communication might be interpreted as blunt or obtuse by one member or straight to the point/not beating about the bush by others (Management, 2014). The more culturally diverse the team, the more important it becomes to understand each member preferred communication styles, to the point of which guidelines may become appropriate (Mayer and Bello, 2012). In an attempt to codify/ quantitate our capacity to function effectively in culturally diverse settings, a cultural intelligence index or CQ has been developed (Van Dyne et al., 2012).

\section{The cultural intelligence four-factor model}

Our degree of CQ is often invoked to explain our potential to adapt and thrive in environments different from the ones we were socialized in. Complimentary to intelligence (IQ) which relates to academic skills and emotional intelligence (EQ) our ability to work with other individuals, in the business setting CQ measures our ability to effectively interact with people who are culturally different to us (Van Dyne et al., 2012). Four inter-related components of CQ have been identified, collectively represented as the "four-factor" model illustrated in components of the CQ four-factor Model (Ang and Van Dyne, 2008) (Bücker et al., 2015):

- Metacognitive CQ, which represents a person's consciousness and awareness of cultural cues during interactions with people from other cultural backgrounds. It has also been described as representing the processes we use to acquire and understand cultural knowledge.

- Acquired through a combination of education and personal experience, cognitive CQ represents our level of competence of the conventions, practices and norms used in different cultural settings. This can include social systems and structures of other cultures and their value systems.

- Motivational CQ assesses the level of interest and energy directed toward learning and functioning in situations characterized by cultural differences people with high motivational CQ express confidence in their personal cross-cultural effectiveness.

- Behavioral CQ measures peoples' ability to exhibit appropriate verbal and nonverbal behavior when interacting with people from different cultures. This may include, for example, the use of culturally appropriate words, tones, gestures and facial expressions.

Significantly within the context of this paper, a study of 73 teams with over 327 members revealed that high levels of $\mathrm{CQ}$ within multi-cultural teams had a positive benefits, equipping the teams to overcome numerous obstacles and potential barriers (Moon, 2013). A number of scales and assessment modalities have been developed to gauge CQ competence, including the Intercultural Adjustment Potential Scale (ICAPS) (Matsumoto et al., 2001), the Cultural Intelligence Scale (CQS) and the Intercultural Developmental Inventory (IDI) (Matsumoto and Hwang, 2013). While the IDI is often deployed for individuals engaging on overseas assignments and the ICAPS for individuals in global leadership roles (Rose et al., 2010), the CQS is seen as a useful assessment for multicultural teams and has been studied 
IJIS

12,3

330

Figure 3.

Components of the

CQS Profile

developed by the

Cultural Intelligence

Center

globally with different audiences (Ng et al., 2009). Pioneered by the Cultural Intelligence Center in the USA, the assessment focuses on specific capabilities, namely, CQ drive (motivation), knowledge (cognition), strategy (metacognition) and action (behavior) (Figure 3; SHRM, 2015).

Respondents receive an integrated assessment including the four key dimensions, and also personal orientation on a total of 10 culture value dimensions, which are compared against tendencies within the 10 largest cultural cluster groupings recognized globally as illustrated in Table 2 (Jung, 1933; Pittenger, 1993). Outputs from the assessment consist of a scoring regimen (0-100 scale) for each of CQ drive, knowledge, strategy and action with 3 or 4 sub-categories in each grouping. A reference scale is provided against worldwide norms for each category and sub-category, recorded as low (bottom 25\%), moderate (middle 50\%) and high (top 25\%). The assessment comes with a workbook allowing respondents to develop and deploy strategies and tactics to address low scoring areas.

The roots of the culture value dimensions used in the CQS assessment instrument have origins in other models, including the PDI, IDV, UAI and LTO indices advanced in the Hofstede analyzes. Though necessarily inexact based on personal circumstances, environment and beliefs, the value dimensions have been mapped against the major cultural clusters into high, medium and low tendencies based on analysis of published studies $(\mathrm{Ng}$ et al., 2009; SHRM, 2015). The mere suggestion of potential differences across the dimensions and the purported range of preferences serves to raise awareness of crosscultural complexities which can factor into team dynamics and signals the importance of CQ knowledge (Figure 4).

The relative contributions of the four CQ dimensions to work-related functions have been investigated and highlight distinct relationships between components. Through consistent patterns, metacognitive CQ and behavioral CQ predict task performance, metacognitive CQ and cognitive $\mathrm{CQ}$ predict both cultural judgment and decision-making ability and motivational CQ plus behavioral CQ predict cultural adaptation. Accordingly, CQS 


\begin{tabular}{|c|c|c|c|c|}
\hline FACTOR & HIGH & MEDIUM & HIGH & ANTONYN \\
\hline $\begin{array}{l}\text { INDIVIDUALISM } \\
\text { Emphasis on individual goals and rights }\end{array}$ & AN, GE, NE & $\mathrm{EE}, \mathrm{LE}$ & $\begin{array}{r}A R, C A, L A, \\
\text { SA, SS }\end{array}$ & $\begin{array}{l}\text { COLLECTIVSN } \\
\text { Emphasis on group goals, personal relations hips }\end{array}$ \\
\hline $\begin{array}{l}\text { LOW POWER DISTANCE } \\
\text { Equality; shared decision-making }\end{array}$ & AN, GE, NE & $\begin{array}{l}\text { CA, EE, LE, } \\
\text { SS }\end{array}$ & AR, LA, SA & $\begin{array}{l}\text { HIGH POWER DISTANCE } \\
\text { Differences in status; superiors make decis ions }\end{array}$ \\
\hline $\begin{array}{l}\text { LOW UNCERTAINTY AVOIDANCE } \\
\text { Emphasis on flexibility and adaptability }\end{array}$ & AN. EE, NE & $\begin{array}{l}\text { AR, CA, GE, } \\
\text { SA, SS }\end{array}$ & LE, LA & $\begin{array}{l}\text { HIGH UNCERTAINTY AVOIDANCE } \\
\text { Emphasis on planning and predictabilits }\end{array}$ \\
\hline $\begin{array}{l}\text { COOPERATIVE } \\
\text { Collaboration, nurturing, and family }\end{array}$ & NE, SS & $\begin{array}{l}\text { AR, CA, EE, } \\
\text { LA, LE, SA }\end{array}$ & $\mathrm{AN}, \mathrm{GE}$ & $\begin{array}{l}\text { COMPETITIVE } \\
\text { Competition, assertiveness, and achievemen }\end{array}$ \\
\hline $\begin{array}{l}\text { SHORT TERM } \\
\text { Emphasis on immediate outcomes }\end{array}$ & $\begin{array}{l}\text { AN, AR, EE, } \\
\text { NE, SS }\end{array}$ & $\begin{array}{l}\text { GE, LA, LE, } \\
\text { SA }\end{array}$ & $\mathrm{CA}$ & $\begin{array}{r}\text { LONG TERN } \\
\text { Emphasis on long term planning }\end{array}$ \\
\hline $\begin{array}{l}\text { LOW CONTEXT-DIRECT } \\
\text { Explicit communications (words alone) }\end{array}$ & AN, GE, NE & EE, LA, LE & $\begin{array}{r}A R, S A, C A, \\
\text { SS }\end{array}$ & $\begin{array}{r}\text { HIGH CONTEXT-INDIRECT } \\
\text { Indirect communications (tone, context. }\end{array}$ \\
\hline $\begin{array}{l}\text { BEING } \\
\text { Emphasis on quality of life }\end{array}$ & $\begin{array}{l}\text { AR, LA, NE, } \\
\text { SS }\end{array}$ & $\begin{array}{l}\text { CA. LE. EE, } \\
\text { SA }\end{array}$ & AN, GE & $\begin{array}{r}\text { DOINC } \\
\text { Emphasis on being busy and meeting goals }\end{array}$ \\
\hline $\begin{array}{l}\text { UNIVERSALISM } \\
\text { Rules; standards that apply to everyone }\end{array}$ & AN, GE, NE & EE, LE & $\begin{array}{l}\text { AR, CA, LA, } \\
\text { SA, SS }\end{array}$ & $\begin{array}{l}\text { PARTICULARISN } \\
\text { Specific, unique standards based on relationships }\end{array}$ \\
\hline $\begin{array}{l}\text { NEUTRAL-NON EXPRESSIVE } \\
\text { Unemotional communication, feelings hidden }\end{array}$ & $\begin{array}{l}\mathrm{CA}, \mathrm{EE}, \mathrm{GE} \\
\mathrm{NE}\end{array}$ & AN, SA & $\begin{array}{r}A R, L A, L E, \\
S S\end{array}$ & $\begin{array}{l}\text { AFFECTIVE-EXPRESSIVE } \\
\text { Expressive communication, feelings sharec }\end{array}$ \\
\hline $\begin{array}{l}\text { MONOCHRONIC-LINEAR } \\
\text { Punctuality; work and personal life separate }\end{array}$ & AN, GE, NE & $\mathrm{CA}, \mathrm{EE}, \mathrm{SA}$ & $\begin{array}{r}A A, L A, L E, \\
S S\end{array}$ & $\begin{array}{l}\text { POLYCHRONIC-NON LINEAF } \\
\text { Multitasking, work and personal combinec }\end{array}$ \\
\hline
\end{tabular}

Cultural
diversity
drives
innovation

331

Figure 4.

A total of 10 culture value dimensions used in CQS assessment

assessment would seem particularly useful for members of newly formed culturally diverse teams, and for individuals relocating to a new (cultural) environment (Ang et al., 2007). More recent studies have attempted to correlate relationships between CQ and individual personality traits (Lievens et al., 2003). The prevailing taxonomy on human personality is commonly referred to as the "Big Five" model (Murugesan and Jayavelu, 2017).

\section{The big five model of personality}

The so-called Big Five model of superordinate factors of personality has gained traction as the basic structure of personality. Its widespread adoption among social researchers stems in part from its ability to consistently emerge in classifying personalities across gender, age, cultural and language denominators and is seen to strongly predict work behaviors across cultures (Judge et al., 2002). Though researchers differ regarding labels used for each of the Five, there is consensus agreement on the factors themselves which are represented in Components of the Big Five personality factors:

- Extraversion (sociable, assertive, ambitious).

- Agreeableness (friendly, trusting, cooperative).

- Conscientiousness (responsible, organized, dependable).

- Emotional stability (control, calm, secure).

- Openness to experience (imaginative, inquiring, artistic).

As the Big Five model has been validated across cultures, there is a natural interest in associations between individual factors and the "four factors" of CQ dimensionality. Based on a number of studies in different settings, relationships have been correlated which allow connections between personality and cultural competence to be made (Ang et al., 2006). Such has far-reaching consequences, given the expanding diversity and mobility of the global workforce and may have special connotations within innovation teams (Elenkov and 
IJIS

12,3

\section{2}

Manev, 2008, 2009). Research has also been conducted to validate the correlations by studying team coaches (Devin, 2017).

Observed correlations and between CQ four-factor and Big Five personality models (Ang et al., 2006):

- Conscientiousness and metacognitive CQ.

- Agreeableness and emotional stability with behavioral CQ.

- Extraversion with cognitive, motivational and behavioral CQ.

- Openness with all four factors of CQ.

\section{Assessing the composition of teams}

The majority of projects conducted in the pharmaceutical industry are through divisional channels with personnel who were hired based on specific skill sets. Teams within these sub-organizations (often called line functions) will be pre-formed and ready to deploy or will assemble then disassemble as needed as projects are identified. Considerable effort has been devoted to our understanding of team dynamics and the contributions of individual members through the assessment of personality traits and modes of engagement. The origins of personality typing date back to the Greco-Roman era with the description of the "four temperaments" by Hippocrates (c.460-c.370 BC). According to this protopsychological theorem, four medical determinants (sanguine, choleric, melancholic and phlegmatic temperaments) were assigned as personalities based on the relative prevalence of bodily fluids and the possibility of mixed categories advanced were personality types overlapped (Merenda, 1987). Some 2,300 years later, application of personality classification and typing became of prime importance in the post-industrialized business world where tasks began to involve diverse teams of workers. One of the most widely used assessment tools is the Myers-Briggs type indicator (MBTI) which is designed to highlight specific personality factors, which may influence behavior in a team (Jung, 1933). Based on the theories of Swiss psychologist Carl Jung the instrument provides an assessment of individuals' preferred stances within team environments, with binary categorization in terms of attitudes (Introvert/Extrovert), lifestyle (Judging/Perceiving) and functions (Sensing/Intuition and Thinking/Feeling) (Pittenger, 1993). The various combinations of tetrads (16 total) are assigned monikers which serve as terms of reference for the individual and team members who will interact with the person (Table 3). Of interest to innovation communities, it is suggested that Apple CEO Steve Jobs was an ENTJ ("Field Marshall"), Albert Einstein INTP (“Architect”) and Thomas Edison an ENTP (“Inventor").

In terms of diversity elements, based on an analysis in $>30$ countries all of the type preferences (E/I, S/N, T/F and J/P) have been observed in each culture studied, however,

Table 3.

The 16 Myers-Briggs type indicators

\begin{tabular}{llll}
\hline ESTP & ESTJ & ISTJ & ISTP \\
\hline Promoter & Supervisor & Inspector & Crafter \\
ENTP & ENTJ & $I N T J$ & INTP \\
Inventor & Field Marshall & Mastermind & Architect \\
ENFP & ENFJ & $I N F J$ & $I N F P$ \\
Champion & Teacher & Counselor & Healer \\
$E S F P$ & $E S F J$ & $I S F J$ & $I S F P$ \\
Performer & Provider & Protector & Composer \\
\hline
\end{tabular}


distribution of the 16 types differ across cultures but retain patterns within these cultures. Across all cultures, (X)STJ is the predominant triad and men in each culture typically respond for $\mathrm{T}$ (c.f. F) at rates ranging from 10-25\% higher than for female respondents (Seegmiller and Epperson, 1987). Jung's work also extended to the related DISC assessment tool, which scrutinizes four areas of behavior, namely, Dominance (in approach to problemsolving), Influence (approach to people), Steadiness (pace and attitude to change) and Compliance (procedures, standards) (Jones and Hartley, 2013).

Another popular assessment tool is the team roles system introduced by Belbin (2010). The instrument is derived from analysis of clusters of behaviors and skills that are required to produce team results and is embodied in a total of nine teams "roles" which stem from three centricities, namely, thinking, action and people-oriented (Table 4).

Belbin role assessment allows team members to identify their preferred roles in a team and also uncover inherent strengths, which they may be unaware of. Though no concrete correlations between the MBTI and Belbin system are evident, the use of the former to gain insight to personality factors and the latter for behavioral pointers has been advocated for effective team building (Higgs, 1996). Although the Belbin and MBTI assessments provide useful pointers for the assembly and successful working of cross-functional teams, for innovation-centric programs the Four Sight Thinking Profile has gained popularity. Its basis is that four fundamental forms of thinking roles are used in creative processes (clarification, ideation, development and implementation) and the relative preferences for each allow categorization for team building (Bratsberg, 2012). Team members develop a chart, plotting high and low preferences for each of the four categories, providing a holistic view on preferences and proclivities that the individual and team can use (Figure 5). For individuals with a single high preference (against statistical means), they are assigned a designation from one of the four categories. Individuals with two or three high preferences are designated into sub-categories and were equivalent in all four categories, as an integrator (Figure 6).

Similarly to other evaluative instruments, the Four Sight program provides participants guidance on the best mode of interaction with colleagues in each of the 15 possible categories, which can be pivotal for team building. For example, it is suggested that ideators who are often regarded as "spontaneous," "imaginative" and "adventurous" should be afforded "constant stimulation," "variety and change" and "scope to dream" by other teams members. Equally importantly, the instrument points to areas where ideators may cause friction for the team e.g. by drawing attention to themselves, being impatient or too abstract, allowing them to modify their approach. The utility of the instrument for innovation teams is underscored by the fact that two of the preferences (ideator, implementer) map directly to the two phases of innovation (initiation, implementation). In terms of relationships with other assessment tools, the communicating author recorded high preference as a driver under Four Sight, typed as ENTJ (Field Marshall) with Myers-Briggs and shaper with Belbin, suggesting action-oriented roles in all three.

While MBTI, Belbin and Four Sight represent assessment tools useful for team assembly and functioning, some other more reflective team profiles have also been advanced including

\begin{tabular}{lllr}
\hline Thinking centric & Action centric & People centric & \\
Plant & Shaper & Coordinator & Table 4. \\
Monitor evaluator & Implementer & Team worker & Resource investigator team \\
Specialist & Completer finisher & roles \\
\hline
\end{tabular}




\section{IJIS \\ 12,3}

\section{4}

Figure 5.

Specimen Four Sight thinking preferences plot

\section{Figure 6.}

The 15 Four Sight Thinking Profiles

\section{Figure 7.}

Hypothetical Team Characters from the Mayo Clinic CFI (left) and The Corporate Startup (right)

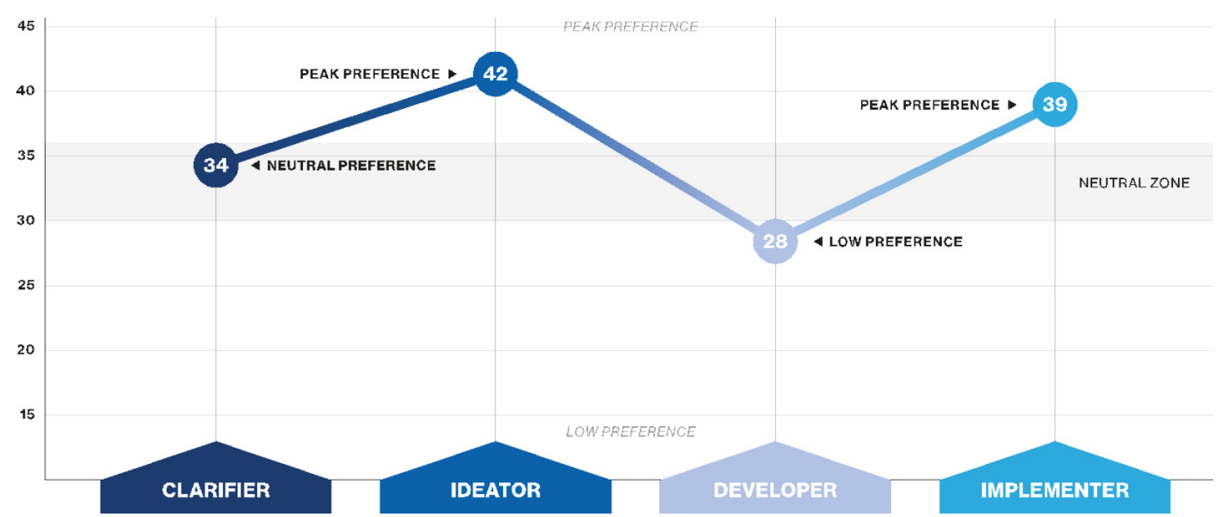

CLARIFIER (CL)

IDEATOR (ID)

DEVELOPER (DV)

IMPLEMENTER (IM)

\section{$\mathrm{CL}+\mathrm{ID}=\mathrm{EARLY} B \mathrm{BRD}$ \\ ID $+D V=$ THEORIST \\ $C L+D V=A N A L Y S T$ \\ ID+IM = DRIVER \\ CL+IM = ACCELERATOR \\ $\mathrm{DV}+\mathrm{IM}=\mathrm{FINISHER}$}

$\mathrm{CL}+\mathrm{ID}+\mathrm{DV}=\mathrm{HARE}$

$\mathrm{CL}+\mathrm{ID}+\mathrm{IM}=$ IDEA BROKER

$\mathrm{CL}+\mathrm{DV}+\mathrm{IM}=\mathrm{REALIST}$

$C L+I D+D V+I M=I N T E G R A T O R$

the 9 innovation team personality types articulated by the Mayo Clinic Center for Innovation (Figure 7) (Van Wulfen, 2009). It is easy to recognize and identify with some of these characters, and many will map onto Belbin and MBTI profiles readily. In a similar vein and with a degree of comedic interpretation (inspired by characters in a children's book series), in their award-winning innovation text The Corporate Startup, Viki, Toma and Gons identify eight innovation characters/caricatures which allow people to relate to Viki et al. (2017). Though certain team members may naturally exude one such persona it is also an

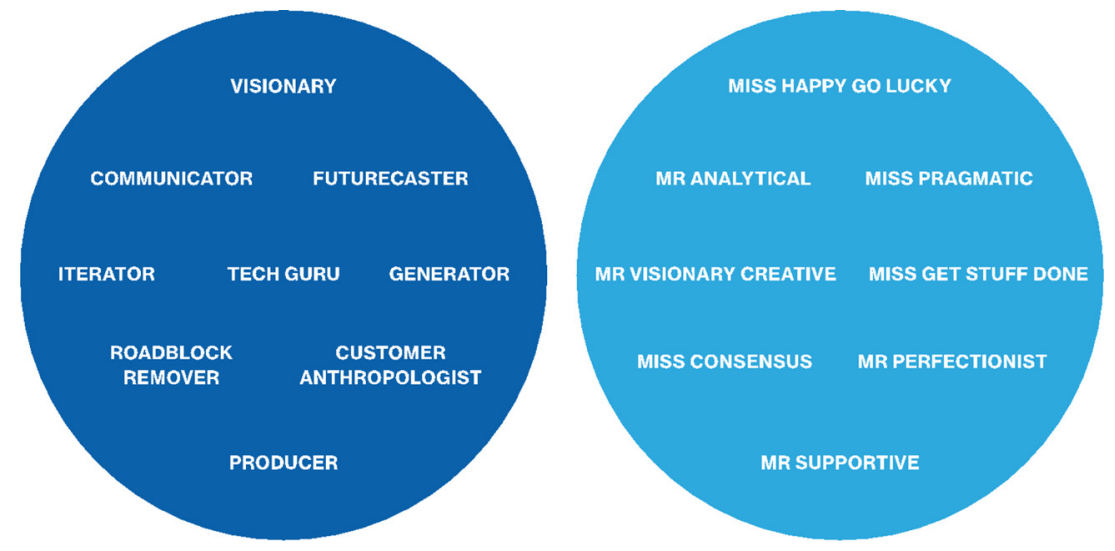


interesting proposition to have team members deliberately adopt one for the purposes of role-play discussion or order that all viewpoints represented by the characters are articulated and appreciated.

No discussion of team roles would be complete without mention of de Bono's six hats (Table 5). The so-called six thinking hats model is a tool to promote parallel then lateral thinking in groups and teams. Each imaginary hat ascribes a designated mindset of an individual, and discussions are choreographed by the wearer of the blue hat, who is the group/team controller (Kivunja, 2015). On socializing the particular topic for discussion, the white hat bearer seeks to clarify information, the red hat bearer delivers an emotional response, the yellow hat bearer positive elements, the black hat bearer cautions and concerns and the green hat bearer creative opportunities. This can be an effective tool for entire teams to adopt a single hat/thinking mode (with the exception of blue which is singular) to align on parallel thinking and then be assigned assorted hats for lateral thinking. The added benefit of this approach is that if conducted with random assignments, individuals may be forced to act outside their comfort zones, promoting personal growth and empathy for team members with differing natural preferences.

The science of developing diverse innovation teams: the science of team science The importance of team diversity to the growth of science, technology and innovation has been recognized and the subject of extensive analysis by various state-level think tanks including the US National Research Council (NRC, 2015). This has led to the emergence of a distinct discipline of inquiry dubbed the SciTS. Numerous studies have systematically assessed the impact of diverse elements such as demographic and task-related diversity (Horwitz and Horwitz, 2007), functional background diversity (Villago et al., 2011) and cultural diversity (Freeman and Huang, 2015). While positive correlations have emerged (Hall et al., 2018), it has also been observed that the larger the team and the greater its diversity, the more potential for subgroups to form, which can create intra-team and interpersonal conflicts (Carton and Cummings, 2013). These so-called "fault lines" can take various forms (Bezrukova, 2013) and require careful management that the team can function effectively in decision-making processes (Jackson et al., 1995). Another key factor for consideration relates to geographic diversity (O'Leary and Cummings, 2007). This can become an acute problem in a hub and spoke models where a central headquarters is a home to the largest number of a team and its culture and communications style dominates the group, creating the potential for an unintended appearance of lower status and power to the satellite communities (Koehne et al., 2012). In terms of best practice for the formation and development of diverse teams, models outlined by Tuckman have often been cited and suggest that critical stages be established as part of a process (Tuckman and Jensen, 1977). With these steps, teams can effectively assemble, perform and then dis-assemble: The critical stages of Team formation, adapted from Tuckman and Jensen (1977)

- Forming: The team is established using either a top-down or bottom-up approach.

- Storming: Team members establish roles and responsibilities. This can often be the onset of turf battles as persons from diverse backgrounds exchange views through a

Blue - Control

Black - Negativity
White-Information

Yellow - Positivity
Red - Emotional

Green-Ideation
Cultural

diversity drives

innovation

335

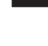


IJIS

12,3

\section{6}

Table 6.

The dialog and debating schemas articulated by Berman (Berman et al., 1977) combination of dialog and debate. If the pressure to reach consensus prematurely is avoided, this phase can be particularly creative as the full team is more likely to input.

- Norming: Team members begin to work together effectively and efficiently, start to develop trust and comfort with one another and learn they can rely on each other.

- Performing: The team works together seamlessly, focuses on a shared goal and efficiently resolves issues or problems that emerge.

- Adjourning or Transforming: Two things can happen when a team accomplishes its initial goal(s):

- Teams may come to a natural end. The team's dissolution should be celebrated and the accomplishments recognized and rewarded.

- The team may take on a new project with a new goal, applying its ability to work together to solve a new problem.

The individual members may participate in other team-based projects and bring valuable learnings to that group, iteratively driving to success factors. Where teams encounter problems during operation, this usually relates to one or more of five "fault-line" factors, which have been characterized (Lencioni, 2002): five factors leading to fault lines in teams:

(1) Absence of trust.

(2) Fear of conflict.

(3) Lack of commitment.

(4) Avoidance of accountability.

(5) Inattention to results.

Within these, fear of conflict is often seen as the most pervasive and insurmountable issue. On any challenging project, the team will be continually exchanging viewpoints from differing perspectives and vulnerability and trust are key issues that need to be addressed. Individuals have widely differing approaches to conflict resolution, and the ThomasKilmann Conflict Mode Instrument was developed to help team members identify their most natural style. The five styles categorized are, namely, competing, accommodating, avoiding, collaborating and compromising (Thomas and Kilmann, 1974). Another key success factor for teams is to understand and navigate the boundaries of dialog and debating schemas (Table 6). As articulated by Berman, very different drivers are associated with each and recognizing these behaviors upfront can allow a team to steer clear of potential conflict forming activities (Berman et al., 1997). Collectively, these SciTS learnings have been found to be equally applicable from fundamental through to translational research and have become recommended reading for any cross-functional and/or diverse team (NIH, 2010).

\begin{tabular}{lll}
\hline Dialog & Principles & Debate \\
\hline - Collaborative & - Characteristics & - Oppositional \\
- Common ground and consensus & - Search goals & - Differences and weaknesses \\
- Open minded & - Attitudes & - Closed minded \\
- Understanding, meaning and agreement & - Listening goals & - Flaws and possible counter arguments \\
- Potential for strength & - Value of other positions & - Source of flaws and weaknesses \\
- Can be probed to identify conflict & - Value of assumptions & - To be defended unquestionably \\
- Potential to refine & - Value of solutions & - Defended to exclusion of all others \\
- Concern for other party, ally & - Engagement mode & - Countering without personal regard \\
\hline
\end{tabular}




\section{Equipping innovation teams for success}

The process of innovation has been described using a variety of terms, but within the context of the pharmaceutical industry, we refer to the ideation, design, initiation and subsequent implementation of novel scientific and technological approaches for the development of new products. Innovation within the industry is typically confined to a restricted number of products, which vary from company to company based on expertise, therapeutic areas and collaborative agreements and the products themselves can be either branded or generic. In the strictest sense, it has been argued that the business does not routinely engage in white space or open innovation and instead largely innovate in areas of competence and familiarity (Nelson, 1991). However, from time to time there are groundbreaking advances that open new avenues in health-care and disrupt the industry e.g. life-saving gene therapies, CAR-T immunotherapies and drug-free all digital therapies which were introduced in the past few years alone. What is well understood within organizations, however, is that competition is ever-present and the discovery, production and management of new medications represents a global challenge that requires continuous forms of innovation throughout the organization. For this reason, organizations study the structure, formation, operation and performance of teams very closely to derive maximum benefit. Measuring the outputs of innovation within a team can sometimes be challenging given the incubation period for marketed products can often exceed a decade, by which time a team's composition will have changed many times. Another more focused approach to innovation within the industry can be to deliberately establish designated innovation teams assigned to tackle specific problems rapidly. In this case, there is a degree of control that can be exerted in the selection of the team, and it is commonly recognized that the diversity of the team (across multiple dimensions) leads to myriad benefits. Fortunately, the modern global pharmaceutical industry is blessed with a highly diverse workforce, making individual team diversity a routine expectation. Our interest and motivation behind the writing of this review are to begin to understand how aspects of team diversity benefit innovation teams. In this context we refer to teams, which have been assembled to execute on a project within a fixed time period, and where the expected outputs will include generation of new knowledge, reducing to practice a new process or product or development of proprietary principles. In each case, a metric could be a generation of a patentable idea, trade secret or publishable concept related to a product intended to enter the marketplace. The recent reports on the correlation between a team's cultural diversity and higher innovation performance (BCG, 2018; Bertelsmann, 2018; Kaasa and Vadi, 2010) are intriguing and are readily relatable. Teams composed of members from diverse backgrounds may approach problems from different perspectives and have different tolerances for risk-taking, both of which are essential attributes needed in creative, innovative teams. A corollary exists, however, in that the more diverse the team, the more potential for culturally inspired misunderstandings to occur, which may be exacerbated under conditions where creative tensions are heightened and time constraints are omnipresent. Accordingly, it is likely that a study of dynamics and operating principles can benefit the entire team, and thus forms a substantial component of this review. Equally importantly, many scientists and engineers will be unaware of the cultural origins of different decision-making processes or communication preferences which over time might be detrimental to the team. For teams established over a long period, it could be expected that members learn each other's preferences, proclivities and idiosyncrasies which attenuates the potential for conflict. In contrast, a freshly formed culturally diverse (innovation) team might need to adapt very quickly, underscoring the need for active assessment and coaching during the onboarding process.

Many of the excellent tools and approaches described herein can provide key learnings for teams and offer unique perspectives tailored to individual circumstances. Through a series of systematic evaluations of the tools and instruments described herein, our internal

\author{
Cultural \\ diversity \\ drives \\ innovation
}

337 
IJIS

12,3

\section{8}

innovation program selected the CQS assessment, FourSight preference and SciTS framework for deployment in innovation teams (Jones et al., 2020). They are being made available to all newly formed teams, actively supported by coaches who are versed in deploying their learnings in mentoring activities and initial results are encouraging (Jones et al., 2020). The formation and normalizing of an innovation team represent two important phases in its development, but it is also imperative that the team's operating principles are appropriate. For any innovation team, openness, trust, candor and psychological safety are pre-requisites for success and to monitor the health of the team an anonymous/confidential scorecard tool is advocated (Figure 8). Adapted from SciTS principles, this is used to record progress or signal advanced warnings at specific intervals during the project, allowing intervention by the assigned coach if necessary (Jones et al., 2020). Aggregate analyzes from these surveys (issued with regular frequency) are shared with teams with emphasis placed on driving to full inclusivity for all team members. We believe with these guidance teams have the maximum chances of success and a framework is in place to monitor impact over

Figure 8.

Team Performance and Inclusivity Tracking Tool

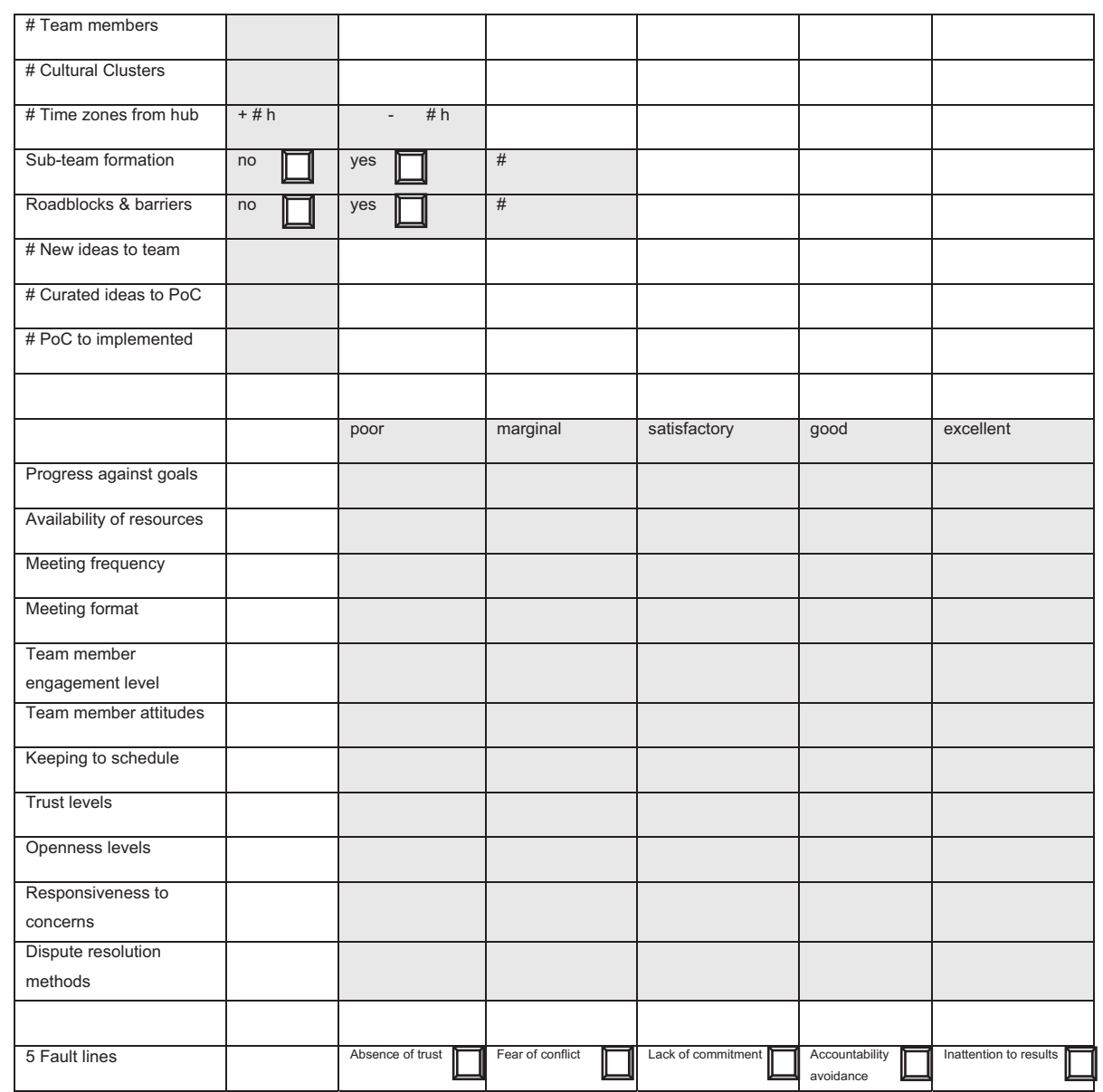


extended periods and multiple cycles. We intend to report the long term findings and implications from these studies in due course (Jones et al., 2020).

\section{Conclusions and implications}

A considerable body of literature supports the notion that cultural diversity in teams correlates with improved innovation performance. Creative tensions in these teams need to be managed appropriately and numerous excellent instruments and strategies are available to leaders. Ideally, these should include cultural assessment (awareness and competence), team dynamics (individual and team integration) and inclusive and transparent operating principles grounded in team science methodology. Systematic analysis using appropriately powered studies and controls will ultimately help quantitate the impact of various components in innovation teams and across programs, although initial observations from our internal innovation program are encouraging (Jones et al., 2020). Such learnings could then be used to inform and guide team development and ultimately allow correlation of diversity elements with predictive outcome metrics. The high levels of cultural diversity in the global pharmaceutical industry make it ideally suited to study these key topics. Another principle to study is whether the behaviors learned in diverse innovation teams are then transferred to new teams that the individuals participate in. Equally interesting is to study whether diverse, established teams diminish their innovative capacity over time due to a normalization process. This could lead to the concept of regular rotations through different teams helping maximize the impact and learnings. With the steady globalization of industries and the increasingly diverse workforce, studies of this nature can play an important role in the success of innovation programs. Scientists, engineers and technologists may seldom read the social science or management literature, but the availability of intuitive tools and instruments to empower their teams to success will ensure continual progress is made. Finally, successful adaptation to remote working conditions mandated by social distancing requires consideration of intra- and inter-team dynamics and the learnings can provide additional benefit for innovation teams operating virtually for extended periods.

\section{References}

Ahuja, G. (2000), "Collaboration networks, structural holes, and innovation: a longitudinal study", Administrative Science Quarterly, Vol. 45 No. 3, pp. 425-455.

Ang, S. and Van Dyne, L. (2008), "Handbook of Cultural Intelligence: Theory, Measures and Applications,", Armonk.

Ang, S., Van Dyne, L. and Koh, C. (2006), "Personality correlates of the four-factor model of cultural intelligence”, Group and Organization Management, Vol. 31, pp. 100-123.

Ang, S., Van Dyne, L., Koh, C., Ng, K.Y., Templer, K.J., Tay, C. and Chandrasekar, N.A. (2007), "Cultural intelligence: its measurement and effects on cultural judgment and decision making, cultural adaptation and task performance", Management and Organization Review, Vol. 3 No. 3, pp. 335-371.

Barrett, L.F., Adolphs, R., Marsella, S., Martinez, A.M. and Pollak, S.D. (2019), "Emotional expressions reconsidered: challenges to inferring emotion from human facial movements", Psychological Science in the Public Interest, Vol. 20 No. 1, pp. 1-68.

Belbin (2010), Roles at Work, Meredith Belbin, 2nd ed., Imprint Routledge, London, doi: 10.4324/ 9780080963242.

Berman, S., Burt, L., Mayo-Smith, D., Stowell, L. and Thompson, G. (1997), Dialogue: turning Controversy into Community, Educators for Social Responsibility, Cambridge, MA. 
IJIS

12,3

Bertelsmann. (2018) "Cultural diversity has a positive impact on innovation”, Bertelsmann Stiftung, available at: www.bertelsmann-stiftung.de/en/our-projects/living-diversity/project-news/ cultural-diversity-has-a-positive-impact-on-innovation/

Bezrukova, K. (2013), "Understanding and addressing faultlines", Presented at the National Research Council's Workshop on Science Team Dynamics and Effectiveness, Washington, DC, available at: http://sites. nationalacademies.org/cs/groups/dbassesite/documents/webpage/dbasse_083763.pdf.

Blau, A. (1977), Inequality and Heterogeneity: A Primitive Theory of Social Structure, Free Press, New York, NY.

Bratsberg, H.M. (2012), "Empathy maps of the four sight preferences”, Creative Studies Graduate Student Master's Projects. Paper 176, available at: https://pdfs.semanticscholar.org/d4e9/ e13a43847ce1ecebec806206f2d8fe676dad.pdf

Bücker, J., Furrer, O. and Lin, Y. (2015), "Measuring cultural intelligence (CQ): a new test of the CQ scale", International Journal of Cross Cultural Management, Vol. 15 No. 3, pp. 259-284.

Campbell, L.G., Mehtani, S., Dozier, M.E. and Rinehart, J. (2013), "Gender-heterogeneous working groups produce higher quality science”, PLoS One, Vol. 8 No. 10, pp. e79147.

Carton, A.M. and Cummings, J.N. (2013), "The impact of subgroup type and subgroup configurational properties on work team performance", Journal of Applied Psychology, Vol. 98 No. 5, pp. 732-758, doi: 10.1037/a0033593.

Clyne, M., Norrby, C. and Warren, J. (2009), Language and Human Relations: Styles of Address in Contemporary Language, Cambridge University Press.

Coles, N.A., Larsen, J.T. and Lench, H.C. (2019), "A Meta-analysis of the facial feedback literature: effects of facial feedback on emotional experience are small and variable”, Psychological Bulletin, Vol. 145 No. 6, doi: 10.1037/bul0000194.

Dakhli, M. and de Clercq, D. (2004), "Human capital, social capital, and innovation: a multi-country study", Entrepreneurship and Regional Development, Vol. 16 No. 2, pp. 107-128.

Devin, H. (2017), "Investigating the relationship between big five personality traits and cultural intelligence on football coaches", Human and Social Studies, Vol. 6 No. 3, pp. 116-131.

Elenkov, D.S. and Pimentel, J.R.C. (2008), "Social intelligence, emotional intelligence, and cultural intelligence: an integrative perspective", In Ang, S. and Van Dyne, L. (Eds) Handbook of Cultural Intelligence, M.E. Sharpe, Armonk, New York, NY, pp. 289-305.

Elenkov, D.S. and Manev, I.M. (2009), "Senior expatriate leadership's effects on innovation and the role of cultural intelligence", Journal of World Business, Vol. 44 No. 4, pp. 357-369.

Freeman, R.B. and Huang, W. (2015), "Collaborating with people like me: Ethnic coauthorship within the United States”, Journal of Labor Economics, Vol. 33 (Suppl. 1), pp. S289-S318.

Freeman, R.B. and Huang, W. (2014), "Collaborating with people like me: Ethnic Co-Authorship within the U.S”, NBER Working Paper No. 19905, National Bureau of Economic Research, Cambridge, MA, available at: www.nber.org/papers/w19905

Fussell, S.R. and Setlock, L.D. (2012), "Multicultural teams", In Bainbridge, W.S. (ed.), Leadership in Science and Technology: A Reference Handbook, Vol. 1, Sage, Thousand Oaks, CA, pp. 255-263.

Gassmann, O. and Schweitzer, F. (2014), "Managing the unmanageable: the fuzzy front end of innovation", In: Gassmann, O, Schweitzer, F (eds) Managing of the Fuzzy Front End of Innovation, Springer, Heidelberg, New York, NY, pp. 3-14.

Gibson, C.B. and Gibbs, J.L. (2006), "Unpacking the concept of virtuality: the effects of geographic dispersion, electronic dependence, dynamic structure, and national diversity on team innovation", Administrative Science Quarterly, Vol. 51 No. 3, pp. 451-495, available at: www. crito.uci.edu/papers/2006/VirtualInnovation.pdf

Gooderham, P. and Nordhaug, O. (2002), “Are cultural differences in Europe on the decline?”, European Business Forum, Vol. 8, pp. 48-53. 
Gudykunst, W.B. and Ting-Toomey, S. (1988), Culture and Interpersonal Communication, SAGE Publications.

Gunnery, S.D. and Hall, J.A. (2014), "The duchenne smile and persuasion”, Journal of Nonverbal Behavior, Vol. 38 No. 2, pp. 181-194.

Hall, E.T. (1977), Beyond Culture, Anchor Press/Doubleday, Garden City, N.Y.

Hall, K.L., Vogel, A.L., Huang, G.C., Serrano, K.J., Rice, E.L., Tsakraklides, S.P. and Fiore, S.M. (2018), "The science of team science: a review of the empirical evidence and research gaps on collaboration in science", American Psychologist, Vol. 73 No. 4, pp. 532-548.

Hampden-Turner, C. and Trompenaars, F. (2006), "Cultural intelligence: is such a capacity credible?", Group and Organization Management, Vol. 31 No. 1, pp. 56-63.

Hareli, S. and Hess, U. (2010), "What emotional reactions can tell us about the nature of others: an appraisal perspective on person perception”, Cognition and Emotion, Vol. 24 No. 1, pp. 128-140.

Herbig, P. and Dunphy, S. (1998), "Culture and innovation", Cross Cultural Management: An International Journal, Vol. 5 No. 4, pp. 13-21.

Higgs, M. (1996), "Overcoming the problems of cultural differences to establish success for international management teams", Team Performance Management: An International Journal, Vol. 2 No. 1, pp. 36-43.

Hofstede, G. (2010), “The GLOBE debate: back to relevance", Journal of International Business Studies, Vol. 41 No. 8, pp. 1339-1346.

Horwitz, S.K. and Horwitz, I.W. (2007), "The effects of team diversity on team outcomes: a Metaanalytic review of team demography", Journal of Management, Vol. 33 No. 6, pp. 987-1015.

Jackson, S.E., May, K.E. and Whitney, K. (1995), “Understanding the dynamics of diversity in decisionmaking teams", In Guzzo, R.A. and Salas, E. (Eds), Team Decision-Making Effectiveness in Organizations, Jossey-Bass, San Francisco, pp. 204-261.

Joecks, J., Pull, K. and Vetter, K. (2013), "Gender diversity in the boardroom and firm performance: what exactly constitutes a “critical mass?”, Journal of Business Ethics, Vol. 118 No. 1, pp. 61-72.

Jones, C.S. and Hartley, N.T. (2013), "Comparing correlations between four-quadrant and five-factor personality assessments", American Journal of Business Education, Vol. 6 No. 4, pp. 459-470.

Jones, G.B., Chirino-Chace, B. and Wright, J.M. (2020), "Cultural diversity drives innovation: modeling in the global pharmaceutical industry", International Journal Innovation and Science, Vol. 12.

Judge, T.A., Heller, D. and Mount, M.K. (2002), "Five-factor model of personality and job satisfaction: a meta-analysis", Journal of Applied Psychology, Vol. 87 No. 3, pp. 530-541.

Jung, C.G. (1933), Psychological Types, Harcourt, Brace, New York, NY.

Kaasa, A. and Vadi, M. (2010), "How does culture contribute to innovation? Evidence from european countries", Economics of Innovation and New Technology, Vol. 19 No. 7, pp. 583-604, doi: 10.1080/ 10438590902987222.

Kivunja, C. (2015), "Using De Bono's six thinking hats model to teach critical thinking and problem solving skills essential for success in the 21st century economy", Creative Education, Vol. 6 No. 3, pp. 380-391, doi: 10.4236/ce.2015.63037.

Koehne, G., Shih, P.C. and Olson, J.S. (2012), "Remote and alone: Coping with being the remote member on the team", In Proceedings of the ACM Conference on Computer Supported Cooperative Work, ACM, New York, NY, pp. 1257-1266.

Krys, K., Melanie Vauclair, C. and Capaldi, C.A. (2016), "Be careful where you smile: culture shapes judgments of intelligence and honesty of smiling individuals", Journal of Nonverbal Behavior, Vol. 40 No. 2, pp. 101-116.

Lencioni, P. (2002), The Five Dysfunctions of a Team, Jossey-Bass, San Francisco.

Lievens, F., Harris, M.M., Van Keer, E. and Bisqueret, C. (2003), "Predicting cross-cultural training performance: the validity of personality, cognitive ability, and dimensions measured by an 
assessment center and a behavior description interview", Journal of Applied Psychology, Vol. 88 No. 3, pp. 476-489.

Lorenzo, R. Voigt, N. Tsusaka, M. Krentz, M. and Abouzahr, K. (2018), "How diverse leadership teams boost innovation”, Boston Consulting Group, available at: www.bcg.com/publications/2018/ how-diverse-leadership-teams-boost-innovation.aspx.

McSweeney, B. (2002), "Hofstede's model of national cultural differences and their consequences: a triumph of faith - a failure of analysis", Human Relations, Vol. 55 No. 1, pp. 89-118.

Management (2014), available at: www.management-issues.com/opinion/6948/cultural-misunderstandingsand-the-elephant-in-the-room/

Mannix, E. and Neale, M.A. (2005), "What differences make a difference? The promise and reality of diverse teams in organizations", Psychological Science in the Public Interest, Vol. 6 No. 2, pp. 31-55.

Martínez-Piva, J.M. (ed) (2009), "Knowledge generation and protection: intellectual property, innovation and economic development", Springer, New York, NY.

Matsumoto, D. and Hwang, H.C. (2013), "Assessing cross-cultural competence: a review of available tests", Journal of Cross-Cultural Psychology, Vol. 44 No. 6, pp. 849-873.

Matsumoto, D., LeRoux, J., Ratzlaff, C., Tatani, H., Uchida, H., Kim, C. and Araki, S. (2001), "Development and validation of a measure of intercultural adjustment potential in Japanese sojourners: the intercultural adjustment potential scale (ICAPS)", International Journal of Intercultural Relations, Vol. 25 No. 5, pp. 483-510.

Mayer, M. and Bello, Y. (2012), "Leading cross cultural teams in today's global marketplace”, PMI Global Congress 2012 - EMEA, Project Management Institute, Marseilles, France. Newtown Square, PA.

Merenda, P.F. (1987), “Toward a Four-Factor theory of temperament and/or personality”, Journal of Personality Assessment, Vol. 51 No. 3, pp. 367-374.

Moon, T. (2013), "The effect of cultural intelligence on performance in multicultural teams", Journal of Applied Social Psychology, Vol. 43 No. 12, pp. 2141-2425.

Murugesan, R. and Jayavelu, R. (2017), "The influence of big five personality traits and self-efficacy on entrepreneurial intention: the role of gender", Journal of Entrepreneurship and Innovation in Emerging Economies, Vol. 3 No. 1, pp. 41-61, doi: 10.1177/2393957516684569.

Nakata, C. and Sivakumar, K. (1996), "National culture and new product development: an integrative review", Journal of Product Innovation and Management, Vol. 13, pp. 462-463.

National Research Council (2015), Enhancing the Effectiveness of Team Science. Committee on the Science of Team Science, The National Academies Press, doi: 10.17226/19007.

Nelson, R.R. (1991), "Why do firms differ, and how does it matter?", Strategic Management Journal, Vol. 12 No. S2, pp. 61-74.

Ng, K.-Y., Van Dyne, L. and Ang, S. (2009), "From experience to experiential learning: Cultural intelligence as a learning capability for global leader development", Academy of Management Learning and Education, Vol. 8, pp. 511-526. Vol,

NIH (2010), Collaboration and Team Science: A Field Guide, Bennett, L.M., Gadlin, H. and Levine-Finley, S. (eds), National Institutes of Health publication

O'Leary, M.B. and Cummings, J.N. (2007), "The spatial, temporal, and configurational characteristics of geographic dispersion in teams", MIS Quarterly, Vol. 31 No. 3, pp. 433-452.

Ozono, H. (2010), "What's in a smile? Cultural differences in the effects of smiling on judgments of trustworthiness", Letters on Evolutionary Behavioral Science, Vol. 1 No. 1, pp. 15-18.

Pittenger, D.J. (1993), "Utility of the Myers-Briggs type indicator", Review of Educational Research, Vol. 63 No. 4, pp. 467-488.

Ramalu, S.S., Rose, R.C., Kumar, N. and Uli, J. (2010), "Doing business in global arena: an examination of the relationship between cultural intelligence and cross-cultural adjustment", Asian Academy of Management Journal, Vol. 15, pp. 79-97. 
Rose, R.C., Ramalu, S.S., Uli, J. and Kumar, N. (2010), "Expatriate performance in international assignments: the role of cultural intelligence as dynamic intercultural competency", International Journal of Business and Management, Vol. 5 No. 8, pp. 76-85.

Seegmiller, R.A. and Epperson, D.L. (1987), "Distinguishing Thinking-Feeling preferences through the content analysis of natural language", Journal of Personality Assessment, Vol. 51 No. 1, pp. $42-52$.

Shane, S. (1993), "Cultural influences on national rates of innovation", Journal of Business Venturing, Vol. 8 No. 1, pp. 59-73.

SHRM (2015), "Cultural intelligence: the essential intelligence for the 21st century", available at: https:// culturalq.com/wp-content/uploads/2016/05/SHRM-report.pdf

Smale, T. (2016), "Why national culture should be at the heart of innovation management", Technology Innovation Management Review, Vol. 6 No. 4, pp. 18-25.

Srinivasan, R. and Martínez, A.M. (2018), "Cross-Cultural and Cultural-Specific production and perception of facial expressions of emotion in the wild", ArXiv, abs/1808.04399.

Stanford, (2016), available at: https://news.stanford.edu/news/2016/february/smiles-jeanne-tsai-021516.html.

Thomas, K.W. and Kilmann, R.H. (1974), Thomas-Kilmann Conflict Mode Instrument, Xicom, a subsidiary of CPP, Mountain View, CA.

Tuckman, B.W. and Jensen, M.A. (1977), "Stages of small-group development revisited", Group and Organization Studies, Vol. 2 No. 4, pp. 419-427.

Uono, S. and Hietanen, J.K. (2015), "Eye contact perception in the west and east: a cross-cultural study", PLoS One, Vol. 10 No. 2, pp. e0118094.

Van Dyne, L., Ang, S., Ng, K.-Y., Rockstuhl, T., Tan, M.L. and Koh, C. (2012), "Sub-dimensions of the four factor model of cultural intelligence: expanding the conceptualization and measurement of cultural intelligence", Social and Personality Psychology Compass, Vol. 6 No. 4, pp. 295-313.

Van Wulfen, G. (2009), "The perfect innovation team”, from innovation: putting ideas into action (best practices report)", APQC, Houston, available at: https://innovationmanagement.se/2013/07/10/ the-perfect-innovation-team/

Viki, T., Toma, D. and Gons, E. (2017), “The corporate startup how established companies can develop successful innovation ecosystems", Vakmedianet.

Villago, S.T., Lukasik, A.J., Belau, M.A. and Briggs, A.L. (2011), "Getting specific about demographic diversity variable and team performance relationships: a metaanalysis", Journal of Management, Vol. 37 No. 3, pp. 709-743.

Wu, M.-Y. (2006), "Hofstede's cultural dimensions 30 years later: a study of Taiwan and the United States", Intercultural Communications Studies XV, Vol. 1, pp. 33-42.

Zheng, L. (2013), "How to show white men that diversity and inclusion efforts need them", Harvard Business Review.

\section{Further reading}

De Abreu Dos Reis, C.R., Sastre Castillo, M.Á. and Roig Dobón, S. (2007), "Diversity and business performance: 50 years of research", Service Business, Vol. 1, p. 257.

Novartis (2020), available at: www.fastcompany.com/company/novartis.

\section{Corresponding author}

Graham Jones can be contacted at: graham.jones@novartis.com

For instructions on how to order reprints of this article, please visit our website:

www.emeraldgrouppublishing.com/licensing/reprints.htm

Or contact us for further details: permissions@emeraldinsight.com 